\title{
TATA RIAS DAN BUSANA TARI SERASAN SEANDANAN DI KABUPATEN OKU SELATAN
}

\author{
Oleh: \\ Nurdin \\ (Dosen FKIP Prodi Pendidikan Sendratasik Universitas PGRI Palembang)
}

\begin{abstract}
ABSTRAK
Tata rias dan busana merupakan salah satu unsure pendukung yang sangat penting dalam sebuah seni pertunjukan tidak terkecuali pada pertunjukan seni tari. Bukan sekedar untuk memperindah dan mempercantik sebuah karya seni bahkan lebih dari itu,tata rias dan busana dijadikan media untuk untuk mengungkapkan dan mengimplementasikan keunikan sejarah dan kekayaan setiap daerah yang ada di Indonesia. Nusantara memiliki ribuan kebudayaan dan kearifan lokal (local genius) yang setiap daerahnya menandung persepektif keindahan yang berbeda satu sama lainnya. Berdasarkan bagian tubuh manusia yang terdiri dari kepala, badan/torso, lengan dan kaki, terdapat perbedaan penggunaan tat arias dan busana setiap daerah yang dapat dilihat berdasarkan topografi, sosial, budaya dan kepercayaan masingmasing. Dalam tari serasan Seandanan tata rias dan busana yang digunakan memiliki makna dan filosopi tersendiri yang melambangkan keunikan Kabupaten OKU Selatan. Metode penelitian ini menggunakan metode deskriptif kualitatif, dengan metode obdervasi,wawancara dan dokumentasi. Teknik keabsahan yang dipilih adalah triangulasi data yang bertujuan untuk menjabarkan hasil penelitian yang akurat dan valid. Hasil penelitian yang dicapai adalah deskripsi tata rias busana tari Serasan Seandanan di Kabupaten OKU Selatan.
\end{abstract}

\section{Kata Kunci: Tata Rias, Busana, Seni Pertunjukan}

\section{A. PENDAHULUAN}

Kebudayaan merupakan sebuah akumulasi kebiasaan dan hasil karya pemikiran sekelompok masyarakat yang disepakati bersama sama dan diteruskan kepada anak cucu serta masyarakat pendatang. Hal ini sesuai dengan pendapat Poerwanto (2000:89) yang menyatakan bahwa sebuah kebudayaan berkembang secara akumulatif, dan semakin lama bertambah banyak serta kompleks. Untuk meneruskannya dari generasi ke generasi, diperlukan suatu sistem komunikasi yang lebih jauh lebih kompleks dari yang dimiliki hewan, ialah bahasa, baik lisan, tertulis maupun dalam bentuk bahasa isyarat. Agar suatu kebudayaan dapat merespon berbagai masalah kelangsungan hidup makhluk manusia dan tetap dipelajari oleh generasi berikutnya, serta tetap 'lestari'. Sejalan dengan pendapat diatas bahwa layaknya manusia yang hidup berkembang dan memiliki keturunan, begitu pula dengan kebudayaan yang ikut hidup bekembang secara turun temurun seiring sejalan dengan kehidupan masyarakat. Tidak ada kebudayaan yang hidup 
tanpa masyarakat begitu pula sebaliknya tidak ada masyarakat yang tidak memiliki kebudayaan.

Bebicara kebudayaan maka akan dihadapkan dengan suatu sistem yang kompleks dan mengikat satu sama lain. Hal ini dikarenakan suatu kebudayaan mengandung unsur-unsur yang saling menunjang dan terkait, dikaji dari pendapat koentjaraningrat, beliau menyatakan bahwa kebudayaan terdiri dari 7 unsur yang korelasinya sangat kuat dan mengikat yang terdiri dari bahasa, system pengetahuan, system kemasyarakatan atau organisasi social, system peralatan hidup dan teknologi,system mata pencaharian, system religi dan kesenian. Setiap unsur kebudayaan ini masing-masing memiliki fungsi dan manfaat yang berbeda dan kompleks yang kesemuanya sangat dibutuhkan untuk menunjang peradaban dalam sebuah masyarkat.

Begitu pula dengan kesenian yang juga banyak memiliki unsur penunjang yang tidak kalah kompleks dan jenis yang beragam sehingga memiliki banyak perspektif keindahan salah satunya adalah seni tari. Seni tari merupakan cabang seni yang berorientasi pada panggung pertunjukan. Setiap seni pertunjukan memiliki unsur pendukung pertunjukan yang dapat meningkatkan dan memaksimalkan estetika penyajian. Hal ini dapat dikaji dari pendapat Murgiyanto (2009:21) yang berpendapat bahwa kesatuan bentuk penyajian sebuah karya seni mencakup gerak, musik, pola lantai, desain, tata rias, busana atau kostum, dan tempat pertunjukan, dimana satu dengan yang lainnya saling terkait dan saling mendukung. Tata rias dan busana atau yang familiar kita kenal dengan istilah kostum merupakan hal pendukung yang sangat urgent dalam setiap penyajiannya dikarenakan kostum memiliki fungsi representasi estetis yang dijadikan media implementasi idendtias kedirian setiap daerah.

Kesenian tari di nusantara memiliki keragaman yang unik dan karakter tradisi yang masih sangat kuat walaupun pada perkembangannya saat ini sdh sangat pesat. Hakl ini dikarenakan sudah tidak ada lagi batasan ruang dan waktu dalam berkarya dan mencari referensi sajian tari. Akan

tetapi ketradisian yang sudah hidup sejak dahulu tetap dipertahankan oleh para pelaku seni tari di nusantara. Salah satunya adalah rias dan kostum tari. Setiap daerah memiliki karakter rias dan kostum yang berbeda dalam setiap karya tarinya. Hal ini dapat disebabkan karena perbedaan topografi, karakter masyarakat, serta sistem kepercayaan yang berbeda-beda. Salah satunya adalah tari sambut Serasan Seandanan dari Kabupaten OKU Selatan. Hal inilah yang mendorong penulis untuk mengangkat perbedaan ini. 


\section{B. METODE PENELIAN}

Pada penelitian ini digunakan metode penelitian deskriftif kualitatif, yaitu metode penelitian dengan cara menyajikan data hasil penjabaran data yang didapat melaui tiga sumber akurat yaitu observasi, wanwancara dan studi dokumentasi yang hasil akhirnya berupa deskripsi data.

Dengan mengutip dari Nyoman, $(2010 ; 306)$ yang menjabarkan bahwa metode penelitian adalah cara yang mengatur prosedur penelitian pada umumnya, sekaligus pelaksanaannya terhadap masing-masing ilmu secara khusus. Metode kualitatif ini memanfaatkan cara-cara penafsiran dengan menyajikannya dalam bentuk deskripsi. Dalam pelaksanaannya data kajian ini didapat dari data promer dan sekunder, dimana data primer yang dimaksud adalah komunitas pelaku seni yang ada di Kabupaten OKU Selatan dan data sekunder berupa dokumentasi dan literasi yang telah tersedia sebelumnya.

\section{PEMBAHASAN DAN HASIL PENELITIAN}

Tata rias dan busana merupakan dua rangkaian pendukung seni pertunjukan yang tidak dapat dipisahkan antara satu dan lainnya terutama pada sebuah garapan karya tari yang merupakan salah satu seni pertunjukan yang ada di nusantara. Dalam hal ini dibutuhkan ketelitian dan kecerdasan serta kecermatan yang tinggi oleh seorang penata busana dalam menyusun dan menentukan rias dan busana serta memadukan keduanya hingga menghasilkan visualisasi yang tidak hanya terlihat cantik akan tetapi harmonis. Maka dari itu dibutuhkan ketelitian dalam penentuan makeup dan pemilihan material kostum yang tepat untuk dapat mendukung kesempurnaan karya tari yang akan disajikan. Berikut ini adalah penjelasan masing-masing dari tata rias dan busana pada karya tari.

\section{Tata Rias}

Tata rias merupakan sebuah usaha untuk mempercantik dan memperindah wajah dan diri setiap manusia khususnya perempuan. Berbeda dengan seni pertunjukan, tata rias dibutuhkan untuk mementukan/ menggambarkan karakter dalam penyajiannya diatas panggung pertunjukan. Menurut Herymawan (dalam Yunita) mengungkapkan bahwa tata rias merupakan seni melukis wajah dengan menggunakan bahanbahan kosmetik untuk mewujudkan karakter yang dibutuhkan sesuai peran yang dilakoni diatas panggung. Selain itu rias juga merupakan aspek dekorasi, yang masing- masing memiliki kapasitas, keistimewaan serta ciri tersendiri yang wajar. Berdasarkan fungsinya rias dibedakan menjadi delapan macam yaitu:

1). Rias aksen merupakan riasan yang yang hanya memberikan tekanan pada rias tersebut hingga mampu memperkuat karakter. Misalnya 
orang batakmemerankan peran sebagai orang batak, maka makeupnya hanya membutuhkan aksen untuk memperjelas garis wajah.

2). Rias jenis merupakan rias yang digunakan untuk mempertegas penari berdasarkan jenis kelamin dan karakter yang diperankan. Misal penari laki-laki memerankan peran perempuan, begitu pula sebaliknya.

3). Rias bangsa merupakan rias yang dibutuhkan untuk memperjelas karakter yang memerankan bangsa lain. Misalkan pemeran bangsa Eropa memerankan peran bangsa Indonesia.

4). Rias usia merupakan riasan yang digunakan untuk merubah usia atau penampilan seorang penari menjadi orang tua atau menjadi anak kecil.

5). Rias tokoh merupakan riasan yang memberikan penjelasan pada tokoh yang di perankan. Misalnya rias yang dibutuhkan untuk memerankan tokoh Sinta, Ramayana dan Srikandi.

6). Rias watak merupakan riasan yang digunakan sebagai penjelas watak yang diperankan pemainya. Misalnya memerankan watak Bawang Merah dan Bawang Putih
7). Rias temporal merupakan riasan yang digunakan berdasarkan waktu ketika pemain melakukan scenario peranannya. Misalnya penari yang memerankan peran seorang putri kemudian berubah menjadi rakyat jelata, itu membutuhkan riasan yang berbeda sebagai penegas.

8). Rias lokal merupakan rias yang digunakan untuk memperjelas keberadaan tempat pemain. Misalnya riasan orang yang sedang sakit dirumah sakit akan berbeda dengan riasan ketika dia sembuh dan keluar dari rumah sakit.

Untuk itu dibutuhkan kepiawaian oleh setiap penata tari, penari dan penata rias untuk memahami karakter berbagai bangsa, watak dan sifat penokohan, anatomi wajah manusia berbagai usia, serta untuk seni pertunjukan tari sangat dibutuhkan pengetahuan tentang karakter dan tokoh perwayangan.

Di dalam sajian tari serasan seandanan digunakan tipe rias tokoh yang setiap penari perempuannya menggunakan riasan cantik layaknya seorang gadis yang cantik dan anggun. 
Berikut beberapa jenis bahan-bahan dan alat make up yang biasa digunakan oleh para penari untuk merias wajah mereka dalam seni pertunjukan.

TABEL 1:

TATA RIAS TARI SERASAN SEANDANAN

\begin{tabular}{|c|c|c|}
\hline $\begin{array}{c}\text { Gambar alat-alat Make Up tari } \\
\text { Serasan Seandanan }\end{array}$ & Keterangan & Fungsi \\
\hline $\begin{array}{llll} \\
\text { (dokumentasi : Aka November } \\
\text { 2017) }\end{array}$ & $\begin{array}{l}\text { Fondation } \\
\text { Bluss on } \\
\text { Eyeshadow } \\
\text { Bedak tabur } \\
\text { Maskara } \\
\text { Lem bulu mata } \\
\text { Alis,Eyeliner } \\
\text { Kuas } \\
\text { Lipstik } \\
\text { Pembersih dan vitamin. } \\
\text { Dalam tata rias alat make } \\
\text { up bisa menggunakan alat } \\
\text { make up merek apa saja } \\
\text { (wawancara Bapak Orpen } \\
\text { Malhadi, M.Sn. } 2 \text { November } \\
\text { 2017) }\end{array}$ & $\begin{array}{c}\text { Dasar bedak } \\
\text { Memerahkan pipi } \\
\text { Memper indah mata } \\
\text { Sesudah fondation } \\
\text { Menebalkan bulu mata } \\
\text { Merekatkan bulu mata } \\
\text { palsu } \\
\text { Pensil alis untuk } \\
\text { membentuk alis } \\
\text { Kuas untuk memoles } \\
\text { alat make up } \\
\text { Memberikan warna } \\
\text { pada bibir } \\
\text { Pembersih untuk } \\
\text { membersihkan muka } \\
\text { dari make up dan } \\
\text { vitamin untuk } \\
\text { membuat make untuk } \\
\text { tahan lama }\end{array}$ \\
\hline
\end{tabular}

\section{Busana}

Busana atau lebih familiar dengan sebutan kostum tari merupakan segala pakaian dan perlengkapan yang digunakan seorang penari diatas panggung sesuai dengan kebutuhannya. Tata pakaian terdiri dari beberapa bagian yaitu:

1) Pakaian dasar, merupakan pakaian yang digunakan sebelum mengenakan pakaian pokoknya. Seperti, korset, legging, tengtop, dan lain sebagainya.
2) Pakaian kaki merupakan pakaian yang digunakan pada kaki, missal celana panjang atau pendek, kaos kaki, sepatu dan lain sebagainya.

3) Pakaian tubuh merupakan pakaian pokok yang digunakan pemain yaitu dimulai dari dada hingga pinggul. Misalnya torso, kace, teratai, sabuk dan lain sebagainya.

4) Pakaian kepala, merupakan pakaian yang dikenakan pada bagian kepala. 
Misalnya sanggul, sunting gunungan, mahkota dan lain sebagainya.

Perlengkapan/aksesoris, adalah perlengkapan yang melengkapi ke empat pakaian tersebut yang bertujuan untuk menghadirkan efek dekoratif pada karakter yang dibawakan. Misalnya perhiasan gelang, anting kalung, pending dan lain sebagainya.

Begitu pula pada kostum tari Serasan Seandanan. Busana yang digunakan juga terdiri dari lima bagian diatas. Pada kostum tari ini dikenal dengan nama kostum angkinan, dimana penari menggunakan pakaian tertutup yang berbahan bludru yang dibbordir tangan dan menggunakan bawahan kain songket yang biasa digunakan disetiap tari sambut di Sumatera Selatan.

Berikut adalah macam-macam pakaian yang digunakan sebagai kostum tari Serasan Seandanan di Kabupaten OKU Selatan.

TABEL 2:

KOSTUMITATA BUSANA TARI SERASAN SEANDANAN

\begin{tabular}{|c|c|c|c|}
\hline No & Nama Busana/Kostum & Gambar Busana & Keterangan \\
\hline 1 & Baju angkinan lepus & & $\begin{array}{l}\text { Baju angkinan lepus adalah } \\
\text { baju adat khas OKU } \\
\text { Selatan }\end{array}$ \\
\hline 2 & Kain Songket & & $\begin{array}{lr}\text { Kain songket } & \text { yang } \\
\text { digunakan adalah } & \text { kain } \\
\text { songket warna merah } & \text { keemasan }\end{array}$ \\
\hline 3 & Pilis (penganggun) & & Pilis adalah hiasan kepala \\
\hline 4 & Bebat (Ikat Pinggang) & & $\begin{array}{l}\text { Ikat pinggang untuk } \\
\text { menahan kain agar tidak } \\
\text { lepas. }\end{array}$ \\
\hline
\end{tabular}




\begin{tabular}{|c|c|c|}
\hline 5 & Teratai & $\begin{array}{l}\text { Teratai OKU Selatan hampir } \\
\text { sama dengan tertai-teratai } \\
\text { lainnya. }\end{array}$ \\
\hline 6 & Selempang & $\begin{array}{l}\text { Selempang yang di } \\
\text { gunakan sama dengan } \\
\text { selempang palembang. }\end{array}$ \\
\hline 7 & $\begin{array}{l}\text { Cempaka Kembang } \\
\text { Goyang }\end{array}$ & $\begin{array}{l}\text { cempaka kembang goyang } \\
\text { adalah hiasan kepala }\end{array}$ \\
\hline 8 & Mayang Setundun & $\begin{array}{l}\text { Mayang setundun adalah } \\
\text { hiasan kepala }\end{array}$ \\
\hline 9 & $\begin{array}{l}\text { Dukat Telapak Jajo } \\
\text { (Kalung) }\end{array}$ & Dukat telapak jajo (Kalung) \\
\hline 10 & $\begin{array}{l}\text { Selendang Sampur Jale } \\
\text { Sutre }\end{array}$ & $\begin{array}{l}\text { Selendang sampur } \\
\text { sutre di ikatkan di } \\
\text { pinggang. }\end{array}$ \\
\hline
\end{tabular}

Gambar : Aka Rusnia November 


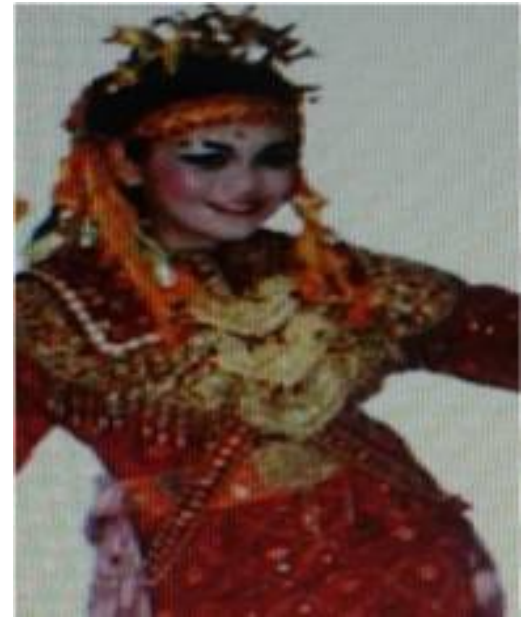

Gambar; Rias dan busana Tari Serasan Seandanan, Sumber, (Aka, November 2017)

\section{SIMPULAN}

Tata rias dan busana sangat dibutuhkan sebagai unsur pendukung dalam pertunjukan karya tari. Tata rias dan busana merupakan dua rangkaian pendukung seni pertunjukan yang tidak dapat dipisahkan antara satu dan lainnya terutama pada sebuah garapan karya tari yang merupakan salah satu seni pertunjukan yang ada di nusantara. Dalam hal ini dibutuhkan ketelitian dan dan kecerdasan serta kecermatan yang tinggi dalam menyusun dan menentukan rias dan busana serta memadukan keduanya hingga menghasilkan visualisasi yang harmonis yang tidak hanya terlihat cantik. Maka dari itu dibutuhkan ketelitian dalam penentuan makeup dan pemilihan material kostum yang tepat untuk dapat mendukung kesempurnaan karya tari yang akan disajikan. Tata rias memiliki delapan jenis yang berbeda sesuai dengan kebutuhan pementasan yaitu terdiri dari rias aksen, rias jenis, rias bangsa, rias usia, rias tokoh, rias watak, rias temporal dan rias lokal. Adapun jenis riasan yang digunakan pada tari Serasan Seandanan yaitu rias tokoh. Sedangkan tata busana terdiri dari beberapa bagian yaitu pakaian dasar, pakaian kaki, pakaian tubuh, pakaian kepala dan aksesoris. Dan kostum yang digunakan pada tari Serasan Seandanan yaitu, baju angkinan lepus, kain songket, dan pilis (penganggon), bebat (ikat Pinggang), teratai, selempang, cempaka kembang goyang, mayang setundun, dukat telapak jajo (kalung), selendang sampur jale sutre.

\section{Daftar Pustaka}

Murgianto, 2009. Ekspresi Jurnal Penelitian dan Penciptaan Seni. Yogyakarta: CV.Arindo Nusa Media.

Poerwanto Hari, 2000. Kebudayaan dan Lingkungan dalam Perspektif Antropologi. Yogyakarta: Pustaka Belajar.

Ratna, Nyoman Kutha. 2010. Metode Penelitian Kajian IImu Budaya Dan IImu Sosial Humaniora Pada Umumnya. Yogyakarta: Pustaka Belajar.

https://www.google.id/amp/s/ibnudin.net/pengertian-ciri-unsur-kebudayaan/amp/ internet-jendela-ilmu.blogspot.com/2011/03/tata-rias-dan-busana.html?m=1 